\title{
Role of PTH1R internalization in osteoblasts and bone mass using a phosphorylation-deficient knock-in mouse model
}

\author{
Nabanita S Datta, Tareq A Samra, Chandrika D Mahalingam, Tanuka Datta and Abdul B Abou-Samra \\ Division of Endocrinology, Department of Internal Medicine, Wayne State University School of Medicine, 1107 Elliman Building, 421 East Canfield Avenue, \\ Detroit, Michigan 48201, USA \\ (Correspondence should be addressed to N S Datta; Email: ndatta@med.wayne.edu)
}

\begin{abstract}
Phosphorylation, internalization, and desensitization of $\mathrm{G}$ protein-coupled receptors, such as the parathyroid hormone $(\mathrm{PTH})$ and PTH-related peptide (PTHrP) receptor (PTH1R), are well characterized and known to regulate the cellular responsiveness in vitro. However, the role of PTH1R receptor phosphorylation in bone formation and osteoblast functions has not yet been elucidated. In previous studies, we demonstrated impaired internalization and sustained cAMP stimulation of a phosphorylation-deficient (pd) PTH1R in vitro, and exaggerated cAMP and calcemic responses to s.c. PTH infusion in pdPTH1R knock-in mouse model. In this study, we examined the impact of impaired PTH1R phosphorylation on the skeletal phenotype of mice maintained on normal, low, and high calcium diets. The low calcium diet moderately reduced $(P<0 \cdot 05)$
\end{abstract}

bone volume and trabecular number, and increased trabecular spacing in both wild-type (WT) and pd mice. The effects, however, seem to be less pronounced in the female pd compared to WT mice. In primary calvarial osteoblasts isolated from 2-week-old pd or WT mice, PTH and PTHrP decreased phosphorylated extracellular signalregulated kinases $1 / 2$ (pERK1/2), a member of mitogenactivated protein kinase, and cyclin $\mathrm{D} 1, \mathrm{a} \mathrm{G}_{1} / \mathrm{S}$ phase cyclin, in vitro. In contrast to $\mathrm{WT}$ osteoblasts, down-regulation of cyclin D1 was sustained for longer periods of time in osteoblasts isolated from the pd mice. Our results suggest that adaptive responses of intracellular signaling pathways in the pd mice may be important for maintaining bone homeostasis.

Journal of Endocrinology (2010) 207, 355-365

\section{Introduction}

Parathyroid hormone (PTH) and PTH-related peptide (PTHrP) activate a common $\mathrm{G}$ protein-coupled receptor (GPCR), PTH1R, which stimulates multiple signaling cascades including the adenylate cyclase/protein kinase A (PKA), phospholipase $\mathrm{C}$ /protein kinase $\mathrm{C}$, and mitogenactivated protein kinases (MAPKs) leading to various biological effects including anabolic and catabolic actions in bone (Datta \& Abou-Samra 2009). Activation of GPCRs by agonists leads to receptor phosphorylation, internalization of the ligand receptor complexes, and desensitization of the hormonal response. Internalization results in dissociation of the agonist from the receptor, and recycling/recovery of the receptor back to the cell membrane and/or its degradation (Lefkowitz et al. 1998). Down-regulation of PTH1R and decreased PTH responsiveness have been extensively studied in renal and osteoblastic cells in vitro (Chao \& Forte 1982, Tamayo et al. 1982, Abou-Samra et al. 1989, Mitchell \& Goltzman 1990, Bellorin-Font et al. 1995, Jongen et al. 1996) and in patients with chronic renal failure in vivo (Olgaard et al. 1982, Gordeladze et al. 1987, Drueke 1996). Phosphorylation-deficient PTH1R (pdPTH1R) does not internalize

normally after PTH challenge; moreover, that display sustained intracellular cAMP response to PTH (Tawfeek et al. 2002). Homozygous knock-in (KI) pdPTH1R mice exhibit decreased serum PTH and phosphate levels and prolonged, exaggerated cAMP and calcemic responses to s.c. PTH infusion (Bounoutas et al. 2006). The sustained elevation of cAMP after PTH challenge, the increased calcemic response to PTH infusion, and the adaptive serum $\mathrm{PTH}$ and phosphorus levels in the pdPTH1R mice suggest that agonist-dependent phosphorylation of the PTH1R plays an important role in receptor function. However, the skeleton of the pdPTH1R mice appeared largely normal.

Our previous studies showed that PTH1R activation up-regulates MAPK phosphatase-1, and down-regulates pERK-MAPK and cyclin D1 in differentiated mature osteoblasts (Chen et al. 2004, Datta et al. 2005, 2010). The physiological role of PTH1R phosphorylation, internalization, and desensitization in bone cells and skeletal development remains largely unknown. In this study, we challenged the pdPTH1R mice with low and high calcium diets to examine the calcemic and skeletal responsiveness during adaptation to extreme diet conditions. Our skeletal analysis suggests that lacking PTH1R phosphorylation in the 
female mice is possibly protective compared to male pd mice on a low calcium diet. In addition, distinct molecular regulation in primary osteoblasts was observed in pdPTH1R KI mice.

\section{Materials and Methods}

Mice

We generated a pdPTH1R KI mouse model using homologous recombination technology as described (Bounoutas et al. 2006). The murine PTH1R gene was cloned from a 129SvJ mouse strain genomic library. A targeting vector was constructed in pcDNA1 that contains an XhoI-EcoRI genomic fragment bearing the seven serine to alanine mutations, a neo-tk cassette flanked by LoxP sites from the pFLOX vector, and an EcoRI fragment from the noncoding region of the PTH1R gene. The vector was linearized with Xhol, purified on agaorse gel, and electroporated into embryonic stem (ES) cells. ES colonies were then screened by Southern blot after KpnI digestion using an external probe (Bounoutas et al. 2006). After transient transfection with cre recombinase, ES cell colonies were selected. Two ES cell colonies were used to generate the KI mice.

All animal protocols were performed in compliance with the Institutional Animal Care and Use Committee for the Use and Care of Animals.

\section{PCR genotyping of pd KI mice}

For routine genotyping, PCR analyses were carried out on DNA extracted from tail biopsies. The sequences of the forward and reverse primers are CCTAAACTCCCACTGTCCTT and CCTCAGGTTCTTGATTCACT respectively, flanking the LoxP insertion site. The sizes of the PCR products are 150 and $450 \mathrm{bp}$ for wild-type (WT) and $\mathrm{pdPTH} 1 \mathrm{R}$ alleles respectively.

\section{High, low, and normal calcium diet study}

Four-week-old animals were placed in new cages with different diets containing $0 \cdot 6 \%$ (normal), $0 \cdot 02 \%$ (low), or $2 \%$ (high) calcium (Harlan Teklad, Madison, WI, USA) until they became 8 weeks old. The experimental conditions (age of mice at the start of experiment, amounts of calcium in the chow, and duration of the experiment) were selected based on a previous experience of the Endocrine Unit Laboratory at the Massachusetts General Hospital, Boston, MA, USA. Retro-orbital blood samples were used to measure PTH, calcium, and phosphate using an ELISA kit for PTH (Immunotopics, San Clemente, CA, USA) or colorimetric assay for calcium and phosphorus (Fisher, Pittsburgh, PA, USA). Bone mineral density (BMD) was measured by PIXImus. Animals were then killed and fixed, and L5 vertebra, distal, and mid-shaft femora were analyzed by micro-computed tomography (micro-CT).

\section{Skeletal phenotyping and micro-CTanalysis}

Micro-CT analyses were performed on the proximal tibiae, distal femora, and L5 vertebrae of WT and pd mice using 3D eXplore Locus micro-CT scanner (GE Healthcare Biosciences, London, ON, Canada) at John D Dingell VA Medical Center (Detroit, MI, USA) or UCT40 (Scanco Medical AG, Basserdorf, Switzerland) at the Orthopedic Biomechanics Laboratory, Beth Israel Deaconess Medical Center, and Harvard Medical School (Boston, MA, USA). The bones were dissected free of soft tissues and fixed in $10 \%$ neutral buffered formalin for $48 \mathrm{~h}$. Images were reconstructed with an isotropic resolution of $27 \mu \mathrm{m}$. Scanning procedure also included the use of a calibration phantom (array of materials at known densities). Analysis of bone parameters was performed using MicroView software (MicroView, GE Healthcare Biosciences). Bone regions of interest were manually segmented using the advanced region of interest (ROI) tool in MicroView.
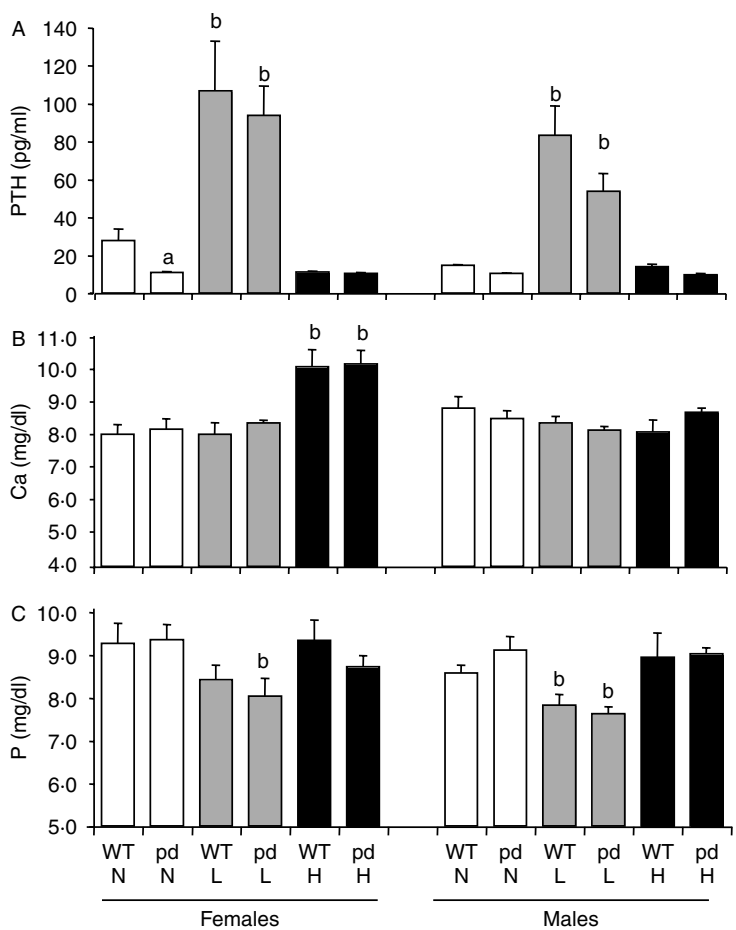

Figure 1 Effect of dietary calcium on serum PTH, total calcium, and phosphate levels of the WT and the pd mice. Four-week-old wild-type and pd littermate mice were fed with the normal $(0 \cdot 6 \%)$, high $(2 \%)$, and low $(0.02 \%)$ calcium diets for 4 weeks, and retroorbital venous blood samples were collected at the end of week 4 of a special diet. (A) PTH, (B) total calcium, and (C) phosphate were measured by ELISA. Data are means \pm s.D. ( $n=6$ from each group). a, $P<0.05$ pd versus WT; $b, P<0.05$ low or high calcium diet versus normal diet. $H$, high calcium diet; $L$, low calcium diet; $\mathrm{N}$, normal calcium diet. pd, phosphorylation-deficient PTH1R; WT, wild-type. 
Bone volume (BV), total volume (TV), trabecular separation (TbSp), and trabecular number $(\mathrm{TbN})$ were analyzed within this ROI using the bone analysis module in MicroView.

\section{Primary osteoblast culture}

Primary osteoblasts were isolated from calvaria of 2-week-old mice by serial digestion (Datta et al. 2005). Briefly, calvaria was dissected, isolated, and subjected to sequential digestions in collagenase A $(2 \mathrm{mg} / \mathrm{ml})$ and trypsin $(0 \cdot 25 \%)$ for 20,40 , and $90 \mathrm{~min}$. Cells from the third digest were rinsed, counted, and plated in aMEM containing 10\% FBS, $100 \mathrm{U} / \mathrm{ml}$ penicillin, and $1 \mu \mathrm{g} / \mathrm{ml}$ streptomycin. Primary cultures were used without passage.

\section{Alkaline phosphatase and von Kossa staining}

Primary cells were plated in 6-well plates with a density of $2 \times 10^{5}$ cells/well, and the medium was replaced twice weekly until the cells were nearly confluent. The medium was changed to osteogenic medium with the addition of ascorbic acid $(50 \mu \mathrm{g} / \mathrm{ml})$ and $\beta$-glycerophosphate $(10 \mathrm{mM})$. The cells were cultured for 5-21 days, and the medium was replaced every 2-3 days with or without $100 \mathrm{nM}$ PTH. Histochemical staining and alkaline phosphatase (ALKP) activity were determined at day 5 using Sigma Fast BCIP/NBT tablets (B5655) and plotted. The mineralization assays were performed using the von Kossa method. At the end of 19 day culture period, the cells were fixed with 95\% EtOH and stained with $\mathrm{AgNO}_{3}$ to detect phosphate deposits in bone nodules as described (Marsh et al. 1995). The deposits
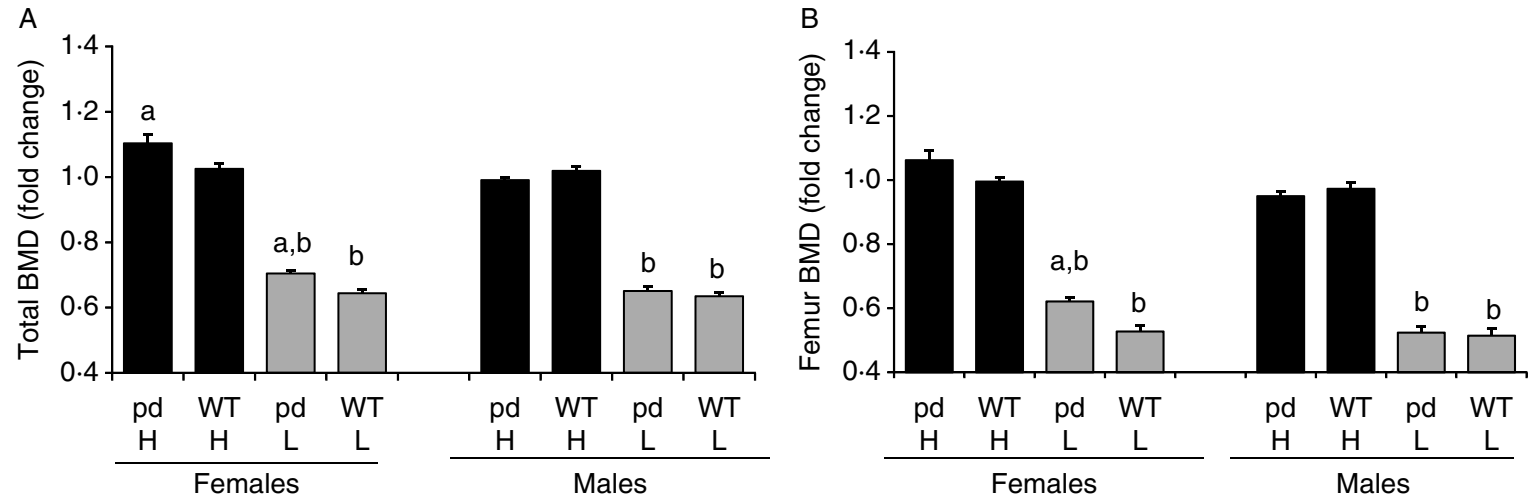

Females

Males

C



Figure 2 Effect of dietary calcium on bone mineral density (BMD) of the WT and the pd mice. Four-week-old WT and pd littermate mice were fed with the normal $(0 \cdot 6 \%)$, high $(2 \%)$, and low $(0 \cdot 02 \%)$ calcium diets for 4 weeks. At the end of week 4 of a special diet $(8$ weeks of age), bone parameters were measured by either PIXImus or micro-CT. Data on the low and high calcium diets were normalized by dividing each $\mathrm{BMD}$ value to its corresponding normal diet value, and the fold changes relative to a normal diet are plotted. A value of $1 \cdot 0$ equals the corresponding BMD value on a normal diet. Data are means \pm s.D. $(n=6$ from each group). $a, P<0 \cdot 05$ pd versus $W T ; b, P<0 \cdot 05$ special calcium diet versus normal diet. $\mathrm{H}$, high calcium diet; $\mathrm{L}$, low calcium diet; $p d$, phosphorylation-deficient PTH1R; WT, wild-type. BMD values of normal diet are for $(A)$, female pd mice, $0 \cdot 0408 \pm 0 \cdot 0014$; female WT mice, 0·0429 $\pm 0 \cdot 0012$; male pd mice, 0·04484 $\pm 0 \cdot 0026$; male WT mice, 0.04476 $\pm 0 \cdot 0016$; for (B), female pd mice, 0·05649 $\pm 0 \cdot 0022$; female WT mice, $0 \cdot 06019 \pm 0 \cdot 0019 ;$ male pd mice, $0 \cdot 06711 \pm 0 \cdot 0079$; male WT mice, $0 \cdot 06583 \pm 0 \cdot 0053$; for $(C)$, female pd mice, $0 \cdot 04859 \pm 0 \cdot 0033$; female WT mice, $0 \cdot 05463 \pm 0 \cdot 005 ;$ male pd mice, $0 \cdot 05407$ $\pm 0 \cdot 0051$; male WT mice, 0.05087 $\pm 0 \cdot 0039$; for (D), female pd mice, 0.05164 $\pm 0 \cdot 0028$; female WT mice, 0.05444 $\pm 0 \cdot 0027$; male pd mice, $0 \cdot 06199 \pm 0 \cdot 0095$; male WT mice, $0 \cdot 06169 \pm 0 \cdot 0072$; for $(E)$, female pd mice, $0 \cdot 297 \pm 0 \cdot 0238$; female WT mice, $0 \cdot 346 \pm 0 \cdot 0309$; male pd mice, $0 \cdot 35857 \pm 0 \cdot 04$; male WT mice, $0 \cdot 34843 \pm 0 \cdot 0283$; for (F), female pd mice, $0 \cdot 01489 \pm 0 \cdot 0016$; female WT mice, $0 \cdot 01847$ $\pm 0 \cdot 0015$; male pd mice, $0 \cdot 01363 \pm 0 \cdot 0011$, male WT mice, $0 \cdot 01301 \pm 0 \cdot 001$. 
of calcium were shown by the formation of opaque mineralized nodules. The number of nodules was counted and plotted as percent relative expression compared to untreated cells. Undifferentiated proliferating osteoblasts were used as a negative control.

\section{Analysis of $m R N A$ by real-time PCR}

Total RNA was extracted from primary osteoblasts using TRIZOL reagent (Invitrogen), and cDNAs were prepared using the TaqMan Reverse Transcription assay system (Applied Biosystems, Foster City, CA, USA). The yield and purity of RNA were estimated spectrophotometrically using A260/A280 ratio. Real-time PCR was performed using StepOnePlus system (Applied Biosystems) using FAM-labeled primers (cyclin D1, \# Mm00432359; GAPDH, \# Mm99999915; ALKP, \# Mm01187117; osteocalcin (OCN), \# AIAAA61; Applied Biosystems). Glyceraldehyde 3-phosphate dehydrogenase (GAPDH) was used as an internal control.

\section{SDS-PAGE and western analysis}

SDS-PAGE and western blot analysis were performed as described previously (Datta et al. 2005). Calvarial osteoblasts were differentiated for 7 days with ascorbic acid $(50 \mu \mathrm{g} / \mathrm{ml})$ and $\beta$-glycerophosphate $(10 \mathrm{mM})$ as above and induced with $100 \mathrm{nM}$ PTH or PTHrP for $10 \mathrm{~min}$ to $5 \mathrm{~h}$ for subsequent experiments. Following induction, cells were washed twice with cold PBS, scraped, and lysed for $30 \mathrm{~min}$ at $4{ }^{\circ} \mathrm{C}$ following sonication with RIPA buffer containing protease inhibitors (Sigma). Cell lysates were cleared by centrifugation at $14000 \mathrm{~g}$ for $45 \mathrm{~min}$. An aliquot of each lysate was removed for protein concentration determination. SDS-PAGE was performed in 10-12\% polyacrylamide. Each lane was loaded with $40-80 \mu \mathrm{g}$ protein of cell lysates. For a given western blot analysis, all lanes received equal protein loads. Pre-stained molecular weight standards were run in parallel lanes. After electrophoresis, the proteins were transferred to a polyvinylidene fluoride (PVDF) membrane (Bio-Rad Laboratories, Inc.) in $25 \mathrm{mM}$ Tris- $\mathrm{HCl}, 192 \mathrm{mM}$ glycine, $20 \% \mathrm{v} / \mathrm{v}$ methanol, and $0 \cdot 01 \% \operatorname{SDS}(\mathrm{pH} 8 \cdot 5$ ) using a semi-dry transfer system (Hoefer, Amersham Biosciences, Piscataway, NJ, USA). Residual protein binding sites on the membrane were blocked by TBST (20 mM Tris- $\mathrm{HCl}, \mathrm{pH} 7 \cdot 6,137 \mathrm{mM}$ $\mathrm{NaCl}$, and $0 \cdot 5 \%$ Tween-20) containing $5 \%$ nonfat dry milk for 3-12 h. The membranes were then incubated with the primary antiserum at room temperature. After washing with TBST, a HRP-conjugated secondary antibody was added for 20-60 min. The protein bands were visualized by autoradiography using an enhanced chemiluminescence detection system (Pierce, Rockford, IL, USA). The protein band intensities on the autoradiograms (all with exposures within the linear range of the film) were quantified using Scion software (Frederick, MD, USA).

\section{Results}

\section{Characteristics of the $p d P T H 1 R$ KI mice}

The high and low calcium diets did not result in significant differences in body weight between WT and pdPTH1R genotypes in male or female mice (not shown).

Serum PTH levels were significantly decreased in female pd mice compared to WT mice fed a normal diet (Fig. 1A). In a low calcium diet, a significant rise in PTH level was observed in both female and male pd and WT mice compared to a normal or a high calcium diet (Fig. 1A). No significant difference in total serum calcium and phosphate levels was observed between WT and pd KI mice fed with a normal diet in both genders (Fig. 1B and C). While serum calcium level was
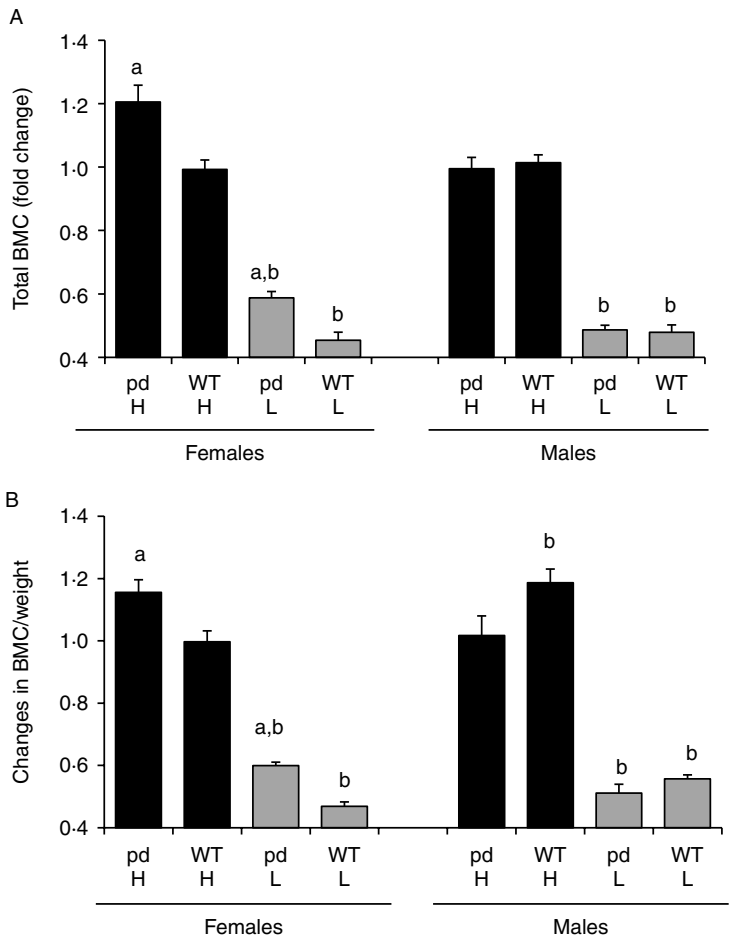

Figure 3 Effect of dietary calcium on bone mineral content (BMC) of the WT and the pd mice. Four-week-old WT and pd littermate mice were fed with the normal $(0 \cdot 6 \%)$, high $(2 \%)$, and low $(0 \cdot 02 \%)$ calcium diets for 4 weeks. At the end of week 4 of a special diet (8 weeks of age), bone parameters were measured by either PIXImus or micro-CT. Data on the low and high calcium diets were normalized by dividing each BMC value to its corresponding normal diet value, and the fold changes relative to a normal diet are plotted. A value of $1 \cdot 0$ equals the corresponding $B M C$ value on a normal diet. Data are means \pm s.D. ( $n=6$ from each group). a, $P<0.05$ pd versus WT; $b, P<0.05$ special calcium diet versus normal diet. $\mathrm{H}$, high calcium diet; $\mathrm{L}$, low calcium diet; $\mathrm{pd}$, phosphorylation-deficient PTH1R; WT, wild-type. BMC values of a normal diet are for $(A)$, female pd mice, $0 \cdot 297 \pm 0 \cdot 0238$; female WT mice, 0.346 $\pm 0 \cdot 0309$; male pd mice, $0 \cdot 35857 \pm 0 \cdot 04$; male WT mice, $0 \cdot 34843 \pm 0 \cdot 0283$; for (B), female pd mice, $0 \cdot 01489 \pm 0 \cdot 0016$; female WT mice, $0 \cdot 01847 \pm 0 \cdot 0015$; male pd mice, $0 \cdot 01363 \pm 0 \cdot 0011$; male WT mice $0 \cdot 01301 \pm 0 \cdot 001$. 
increased in WT and pd female mice fed with a high calcium diet compared to a normal or a low calcium diet, no change in serum calcium was noted in male WT or pd mice fed with the normal, low, or high calcium diets (Fig. 1B). Although both female WT and pd mice showed a tendency of decreased serum phosphate levels on a low calcium diet compared to a normal or a high calcium diet (Fig. 1C), the difference was significant $(P<0 \cdot 05)$ only in pd mice, not in WT mice, compared to a normal diet. In contrast, both WT and pd males showed significantly $(P<0 \cdot 05)$ lower phosphate levels in a low calcium diet compared to a normal or a high calcium diet (Fig. 1C). Our previous study showed that following $12 \mathrm{~h}$ starvation, 8-week-old pd mice exhibit decreased serum phosphate level compared to WT mice in a normal diet (Bounoutas et al. 2006). Effect of dietary phosphorus on serum concentration is a well-known phenomenon; this may explain why no significant difference in phosphate levels is observed between WTand PD mice in the present study where the mice were not starved for $12 \mathrm{~h}$ before serum sampling.

\section{Changes in BMD and bone mineral content in WT and pd mice fed the low and high calcium diets}

Figs 2 and 3 show the changes in total BMD, spine and femur BMD, and bone mineral content (BMC) in WT and pd female or male mice fed a low or a high calcium diet compared to a normal diet. The values for total BMD and total BMC are included in the legends of Figs 2 and 3 respectively, and the fold changes of total BMD and total $\mathrm{BMC}$ in the high and low $\mathrm{Ca}$ diets with respect to a normal diet are plotted. The high calcium diet increased the total and spine BMD and total BMC in pd female mice compared to WT female mice (Figs 2A and C and 3A and $B)$. In contrast, no change in total BMC was observed between $\mathrm{pd}$ and WT male mice (Fig. 3A). Both pd and WT females and males showed a dramatic decrease in total, spine, femoral, and diaphyseal BMD when fed with a low calcium diet (Fig. 2A-D). When corrected to body weight, only pd female mice and WT male mice fed with a high calcium diet showed a significant increase in BMC/weight (Fig. 3B). In contrast, the low calcium diet significantly decreased $\mathrm{BMC} /$ weight in both genders for each genotype (Fig. 3B).

Micro-CT analysis of tibiae, femora, and L5 vertebrae of 8-week-old mice fed with the normal and low calcium diets

Since the BMD and BMC were dramatically decreased in pd and WT mice fed with a low calcium diet, we performed a detailed micro-CT analysis of 8-week-old tibiae, femora, and L5 vertebrae of these mice (Tables 1 and 2). The low calcium diet decreased the BV/TV,

Table 1 Micro-computed tomography analysis of vertebrae and femora of the WT and the pd female mice

\begin{tabular}{|c|c|c|c|c|}
\hline & \multicolumn{2}{|c|}{ WT females } & \multicolumn{2}{|c|}{ pd females } \\
\hline & Normal diet & Low Ca & Normal diet & Low Ca \\
\hline \multicolumn{5}{|l|}{ L5 Vert } \\
\hline BV/TV (\%) & $22 \cdot 8 \pm 1 \cdot 5$ & $12 \cdot 4 \pm 1 \cdot 4^{+}$ & $22 \cdot 7 \pm 1 \cdot 3$ & $11 \cdot 2 \pm 1 \cdot 1^{+}$ \\
\hline TbTh (mm) & $52 \cdot 9 \pm 0 \cdot 7$ & $48 \cdot 2 \pm 1 \cdot 0^{+}$ & $52 \cdot 2 \pm 1 \cdot 5$ & $49 \cdot 6 \pm 1 \cdot 3^{+}$ \\
\hline $\mathrm{TbN}(1 / \mathrm{mm})$ & $4 \cdot 58 \pm 0 \cdot 23$ & $3 \cdot 37 \pm 0 \cdot 32^{+}$ & $4 \cdot 53 \pm 0 \cdot 33$ & $2 \cdot 77 \pm 0 \cdot 17^{*,+}$ \\
\hline TbSp (mm) & $207 \pm 12$ & $296 \pm 33^{+}$ & $215 \pm 18$ & $364 \pm 20^{*,+}$ \\
\hline Conn & $158 \cdot 6 \pm 15 \cdot 9$ & $87 \cdot 5 \pm 14 \cdot 6^{+}$ & $166 \cdot 9 \pm 13 \cdot 6$ & $81 \cdot 8 \pm 20 \cdot 1^{\dagger}$ \\
\hline SMI & $1 \cdot 15 \pm 0 \cdot 17$ & $1.98 \pm 0.13^{+}$ & $1 \cdot 26 \pm 0 \cdot 19$ & $2 \cdot 06 \pm 0 \cdot 18^{\dagger}$ \\
\hline MinD & $920 \pm 20$ & $661 \pm 25^{+}$ & $897 \pm 27$ & $665 \pm 32^{+}$ \\
\hline \multicolumn{5}{|l|}{ Distal femur } \\
\hline BV/TV $(\%)$ & $10 \cdot 03 \pm 1 \cdot 37$ & $5 \cdot 92 \pm 0 \cdot 49^{+}$ & $10 \cdot 90 \pm 1 \cdot 09$ & $7 \cdot 06 \pm 0 \cdot 85^{*,+}$ \\
\hline TbTh (mm) & $53 \cdot 5 \pm 2 \cdot 0$ & $48 \cdot 8 \pm 1 \cdot 8^{\dagger}$ & $51 \cdot 2 \pm 1 \cdot 5^{*}$ & $50 \cdot 0 \pm 1 \cdot 2$ \\
\hline $\mathrm{TbN}(1 / \mathrm{mm})$ & $3 \cdot 22 \pm 0 \cdot 29$ & $2 \cdot 43 \pm 0 \cdot 13^{+}$ & $3 \cdot 73 \pm 0 \cdot 35^{*}$ & $2 \cdot 61 \pm 0 \cdot 13^{*,+}$ \\
\hline $\mathrm{TbSp}(\mathrm{mm})$ & $315 \pm 32$ & $415 \pm 21^{+}$ & $266 \pm 29^{*}$ & $385 \pm 25^{*,+}$ \\
\hline Conn & $70 \cdot 4 \pm 7 \cdot 1$ & $38 \cdot 2 \pm 4 \cdot 5^{+}$ & $88 \cdot 6 \pm 16 \cdot 3 *$ & $52 \cdot 4 \pm 10 \cdot 8^{*,+}$ \\
\hline SMI & $2 \cdot 79 \pm 0 \cdot 22$ & $2 \cdot 92 \pm 0 \cdot 11$ & $2 \cdot 80 \pm 0 \cdot 10$ & $2 \cdot 76 \pm 0 \cdot 12 *$ \\
\hline MinD & $913 \pm 45$ & $686 \pm 20^{+}$ & $881 \pm 11^{*}$ & $719 \pm 44^{+}$ \\
\hline \multicolumn{5}{|c|}{ Mid-shaft femur } \\
\hline TA & $1 \cdot 67 \pm 0 \cdot 05$ & $1 \cdot 46 \pm 0 \cdot 09^{+}$ & $1 \cdot 60 \pm 0.07^{*}$ & $1 \cdot 48 \pm 0 \cdot 08^{\dagger}$ \\
\hline $\mathrm{BA}$ & $0.625 \pm 0.029$ & $0.313 \pm 0.033^{+}$ & $0 \cdot 610 \pm 0 \cdot 044$ & $0 \cdot 402 \pm 0 \cdot 030^{*,+}$ \\
\hline MA & $1 \cdot 050 \pm 0.053$ & $1 \cdot 146 \pm 0.082^{+}$ & $0.986 \pm 0.039 *$ & $1 \cdot 081 \pm 0.061^{*,+}$ \\
\hline BA/TA (\%) & $37 \cdot 3 \pm 1 \cdot 9$ & $21 \cdot 5 \pm 2 \cdot 1^{+}$ & $38 \cdot 2 \pm 1 \cdot 5$ & $27 \cdot 1 \pm 1 \cdot 4^{*,+}$ \\
\hline Cort Thick & $143 \cdot 5 \pm 10 \cdot 4$ & $78 \cdot 1 \pm 9 \cdot 4^{\dagger}$ & $146 \cdot 0 \pm 8 \cdot 7$ & $97 \cdot 1 \pm 5 \cdot 9^{*,+}$ \\
\hline Cort MinD & $1409 \pm 14$ & $1299 \pm 36^{+}$ & $1409 \pm 15$ & $1340 \pm 27^{*,+}$ \\
\hline
\end{tabular}

WT, wild-type; pd, phosphorylation-deficient PTH1R; Ca, calcium. Values are mean \pm s.D. ( $n=6$ from each group); ${ }^{*} P<0.05$ versus $\mathrm{WT} ;{ }^{\dagger} P<0 \cdot 05$ low calcium diet versus normal. BV/TV, bone volume/total volume; TbTh, trabecular thickness; TbN, trabecular number; MinD, mineral density; Conn, connectivity; SMI, structure model index; TA, total area; BA, bone area; MA, marrow area; Cort Thick, cortical thickness; Cort MinD, cortical mineral density. 
Table 2 Micro-computed tomography analysis of vertebrae and femora of the WT and the pd male mice

\begin{tabular}{|c|c|c|c|c|}
\hline & \multicolumn{2}{|c|}{ WT males } & \multicolumn{2}{|c|}{ pd males } \\
\hline & Normal diet & Low Ca & Normal diet & Low Ca \\
\hline \multicolumn{5}{|l|}{ L5 Vert } \\
\hline BV/TV (\%) & $27 \cdot 9 \pm 1 \cdot 5$ & $17 \cdot 4 \pm 1 \cdot 1^{+}$ & $26 \cdot 3 \pm 1 \cdot 4^{*}$ & $16 \cdot 2 \pm 1 \cdot 2^{*,+}$ \\
\hline $\mathrm{TbTh}(\mathrm{mm})$ & $50 \cdot 3 \pm 1 \cdot 9$ & $48 \cdot 4 \pm 0 \cdot 8^{+}$ & $50 \cdot 9 \pm 1 \cdot 3$ & $48 \cdot 2 \pm 1 \cdot 0^{+}$ \\
\hline $\mathrm{TbN}(1 / \mathrm{mm})$ & $5 \cdot 99 \pm 0.30$ & $4 \cdot 08 \pm 0 \cdot 26^{+}$ & $5 \cdot 58 \pm 0 \cdot 36^{*}$ & $4 \cdot 23 \pm 0 \cdot 18^{\dagger}$ \\
\hline $\mathrm{TbSp}(\mathrm{mm})$ & $157 \pm 9$ & $241 \pm 17^{\dagger}$ & $171 \pm 14^{*}$ & $233 \pm 13^{+}$ \\
\hline Conn & $278 \cdot 2 \pm 30 \cdot 2$ & $140 \cdot 0 \pm 17 \cdot 6^{+}$ & $264 \cdot 2 \pm 35 \cdot 2$ & $137 \cdot 3 \pm 22 \cdot 6^{+}$ \\
\hline SMI & $1 \cdot 04 \pm 0 \cdot 12$ & $1 \cdot 60 \pm 0 \cdot 17^{\dagger}$ & $1 \cdot 26 \pm 0 \cdot 16^{*}$ & $1 \cdot 88 \pm 0 \cdot 167^{*,+}$ \\
\hline MinD & $919 \pm 37$ & $720 \pm 24^{+}$ & $896 \pm 37$ & $726 \pm 36^{+}$ \\
\hline \multicolumn{5}{|l|}{ Distal femur } \\
\hline BV/TV (\%) & $17 \cdot 01 \pm 4 \cdot 07$ & $8.68 \pm 0.96^{\dagger}$ & $18 \cdot 34 \pm 4 \cdot 10$ & $8.98 \pm 0.99^{+}$ \\
\hline TbTh (mm) & $55 \cdot 8 \pm 8 \cdot 3$ & $49 \cdot 0 \pm 1 \cdot 1^{+}$ & $53 \cdot 3 \pm 4 \cdot 8$ & $48 \cdot 1 \pm 1 \cdot 6^{+}$ \\
\hline $\mathrm{TbN}(1 / \mathrm{mm})$ & $4.73 \pm 0.43$ & $3 \cdot 20 \pm 0.33^{+}$ & $4.67 \pm 0.66$ & $3 \cdot 45 \pm 0 \cdot 28^{+}$ \\
\hline TbSp $(\mathrm{mm})$ & $208 \pm 24$ & $301 \pm 13^{+}$ & $213 \pm 33$ & $291 \pm 24^{+}$ \\
\hline Conn & $154 \cdot 9 \pm 28 \cdot 8$ & $67 \cdot 8 \pm 10 \cdot 6^{+}$ & $176 \cdot 1 \pm 44 \cdot 1$ & $75 \cdot 5 \pm 15 \cdot 3^{+}$ \\
\hline SMI & $2 \cdot 41 \pm 0.019$ & $2 \cdot 79 \pm 0 \cdot 11^{+}$ & $2 \cdot 18 \pm 0 \cdot 38$ & $2 \cdot 78 \pm 0 \cdot 11^{+}$ \\
\hline MinD & $934 \pm 49$ & $703 \pm 31^{+}$ & $908 \pm 78$ & $753 \pm 33^{*,+}$ \\
\hline \multicolumn{5}{|c|}{ Mid-shaft femur } \\
\hline TA & $1 \cdot 86 \pm 0 \cdot 14$ & $1 \cdot 58 \pm 0 \cdot 07^{+}$ & $1 \cdot 88 \pm 0 \cdot 21$ & $1 \cdot 60 \pm 0.06^{+}$ \\
\hline $\mathrm{BA}$ & $0.736 \pm 0.088$ & $0.333 \pm 0.049^{\dagger}$ & $0 \cdot 758 \pm 0 \cdot 111$ & $0 \cdot 386 \pm 0.082^{\dagger}$ \\
\hline MA & $1.129 \pm 0.096$ & $1 \cdot 250 \pm 0.043^{+}$ & $1 \cdot 118 \pm 0 \cdot 120$ & $1 \cdot 213 \pm 0.052^{+}$ \\
\hline BA/TA (\%) & $39 \cdot 4 \pm 3 \cdot 2$ & $21 \cdot 0 \pm 2 \cdot 3^{+}$ & $40 \cdot 3 \pm 2 \cdot 7$ & $24 \cdot 0 \pm 4 \cdot 4^{+}$ \\
\hline Cort Thick & $164 \cdot 5 \pm 18 \cdot 9$ & $74 \cdot 8 \pm 10 \cdot 8^{\dagger}$ & $164 \cdot 4 \pm 15 \cdot 4$ & $85 \cdot 1 \pm 15 \cdot 5^{\dagger}$ \\
\hline Cort MinD & $1402 \pm 21$ & $1276 \pm 30^{+}$ & $1380 \pm 13^{*}$ & $1283 \pm 25^{+}$ \\
\hline
\end{tabular}

WT, wild-type; pd, phosphorylation-deficient PTH1R; Ca, calcium. Values are mean \pm s.D. $(n=6$ from each group); ${ }^{*} P<0.05$ versus $\mathrm{WT} ;{ }^{\dagger} P<0.05$ low calcium diet versus normal. BV/TV, bone volume/total volume; TbTh, trabecular thickness; TbN, trabecular number; MinD, mineral density, Conn, connectivity; SMI, structure model index; TA, total area; BA, bone area; MA, marrow area; Cort Thick, cortical thickness; Cort MinD, cortical mineral density.

trabecular thickness (TbTh) and $\mathrm{TbN}$, and mineral density (MinD) and connectivity (Conn), and increased the TbSp in the vertebrae and distal femur. Similarly, the low calcium diet decreased the mid-shaft bone strength parameters, total area (TA), bone area (BA), (BA/TA), cortical thickness (Cort Thick), and cortical mineral density (Cort MinD), and increased the marrow area (MA) in both the pd and the WT mice (Tables 1 and 2).

Comparing the pd mice to the WT mice revealed that the low calcium diet affected more dramatically several of the micro-CT parameters of bones of the pd female than those of the WT female. The low calcium diet negatively affected several of the bone parameters of the L5 vertebra in the pd female mice compared to the WT female mice. For instance, the low calcium diet decreased L5 TbN to a lower level in the pd females than in the WT females $(2 \cdot 77 \pm 0 \cdot 17$ versus $3 \cdot 37 \pm 0.32 ; P<0 \cdot 05)$ and increased the L5 and TbSp more in the pd females than in the WT females $(364 \pm 20$ versus $296 \pm 33 ; P<0 \cdot 05)$. In contrast, the bone parameters of the distal femur (BV/TV, TbN, TbSp, and Conn) and the mid-shaft (BA, BA/TA, Cort Thick, and Cort MinD) were positively affected by the pd genotype (Table 1). In contrast to the female mice, there was no significant difference in most of the micro-CT parameters of bones between the male pd and the male WT mice (Table 2).
Effect of impaired PTH1R phosphorylation on mineralization of primary calvarial osteoblasts isolated from 2-week-old pdPTH1R mice

To understand the cellular mechanism leading to the changes in bone mass observed in pd mice, we examined whether primary calvarial cells obtained from WT and pd mice contained the same number of osteoprogenitor cells. No significant group differences in total osteoblasts per calvaria were found (data not shown). Calvarial cells from 2-week-old mice were plated in 6-well plates, and degree of differentiation (colony-forming unit (CFU)-ALKP and ALKP activity) and mineral deposition (von Kossa staining and CFU osteoblasts) were assessed. Compared to undifferentiated negative controls, differentiated cells showed significant mineralization in osteoblasts isolated from the WT and the pd mice (Fig. 4A). There was minimum to no difference in mineralization between the osteoblast cultures isolated from either male or female pd mice compared to respective WT controls. Continuous PTH treatment significantly down-regulated mineralized nodule formation in both WT and pd osteoblasts (Fig. 4A). ALKP activity was significantly increased in PTH-treated osteoblasts compared to untreated cultures isolated from the WT or the pd male and female mice (Fig. 4B). Gene expression analysis showed significant down-regulation of OCN mRNA expression in both WT and pd cells following continuous PTH treatment (Fig. 4C). In contrast, the changes 
A
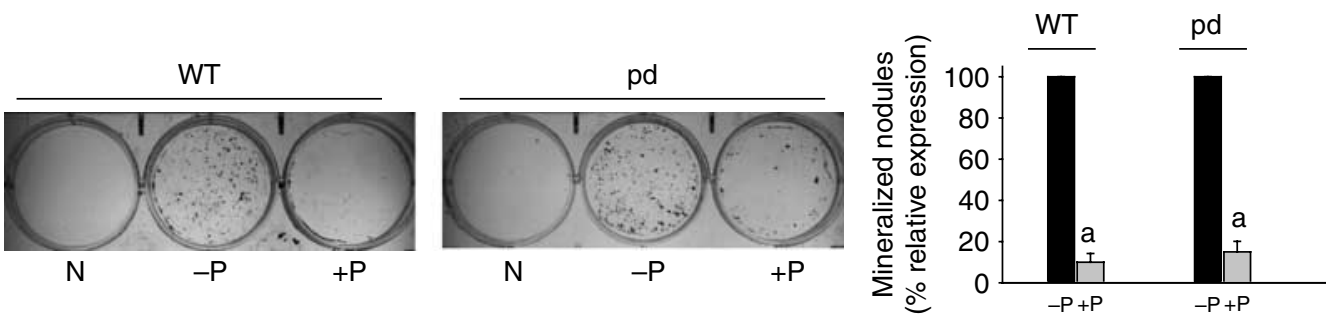

B
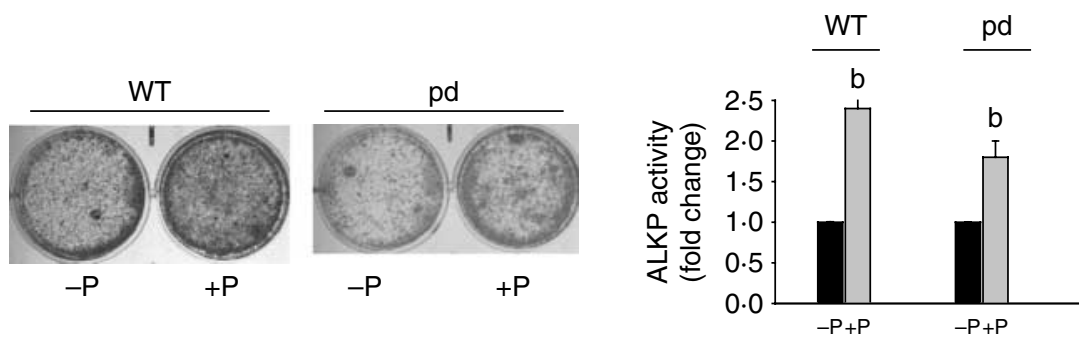

C
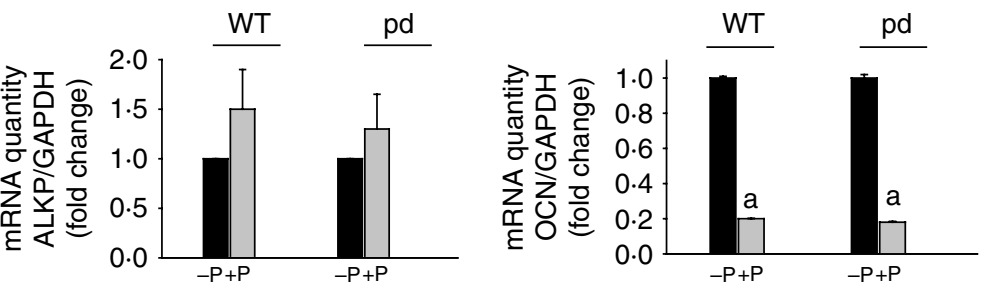

Figure 4 Effect of PTH on differentiation of primary calvarial osteoblasts isolated from the WT and the pd mice. (A) Representative von Kossa staining of primary calvarial osteoblasts isolated from the WT and the pd mice. The cells were differentiated with ascorbic acid and $\beta$-glycerophosphate for 19 days with or without $100 \mathrm{nM}$ PTH. Following von Kossa staining, mineralized bone nodules of phosphate deposits were counted. The results are expressed as percent relative expression of bone nodules without PTH treatment. Results from representative culture plates are shown. (B) Primary calvarial osteoblasts isolated from the WT and the pd mice were differentiated for 5 days as above, with and without PTH. Results from representative ALKP staining of 5 day differentiated cultures are shown. ALKPactivity was measured in duplicate plates, and the results are expressed as fold change with respect to untreated cells. (C) Real-time PCR analysis was performed to analyze RNA extracted from differentiated WT and pd calvarial osteoblasts with and without PTH treatment. GAPDH was used as an internal control. Results are expressed as mean \pm s.D. from five to six independent experiments. a, $P<0 \cdot 001$. P, PTH; pd, phosphorylation-deficient PTH1R; WT, wild-type; N, undifferentiated control.

in ALKP mRNA levels with PTH treatment of earlydifferentiated osteoblast cultures were not significant (Fig. 4C).

\section{$p E R K-M A P K$ and cyclin D1 are down-regulated following $P T H r P$ treatment in primary calvarial osteoblasts isolated from the $W T$ and the pd mice}

To determine whether impaired PTH1R phosphorylation and internalization are important for the molecular regulation of osteoblasts, we cultured primary cells from pd and WT littermates or age-matched controls and differentiated them for 7 days. While there were no differences in the total ERK1/2 protein levels, results indicated significant downregulation of pERK1/2 in WT and pd calvarial osteoblastic cells following $100 \mathrm{nM} \mathrm{PTH}$ or PTHrP treatment for $10 \mathrm{~min}$ (Fig. 5). PTH or PTHrP significantly down-regulated protein (Fig. 6A) or mRNA (Fig. 6B) expression of cyclin D1 at 5 and
$1 \mathrm{~h}$ of incubation respectively in WT and pd cells. However, unlike in the WT cells, the pd cells exhibited a sustained down-regulation of cyclin D1 protein expression after $24 \mathrm{~h}$ incubation with PTH or PTHrP (Fig. 6A).

\section{Discussion}

Several hormonal systems have been characterized in vitro that describe internalization of GPCRs and desensitization of the hormonal responses. Desensitization of GPCRs involves GPCR kinases (GRKs) that phosphorylate C-terminal serine and threonine residues of agonist-stimulated GPCRs and binding of the members of the $\beta$-arrestins (Pitcher et al. 1998, Oakley et al. 2001). $\beta$-Arrestin 1 and 2 knockout mice and transgenic mice with targeted overexpression of a peptide inhibitor of GRK2 have been used to study the role of 




Figure 5 Expression of pERK1/2 in differentiated primary calvarial osteoblasts isolated from the WT and the pd mice. Differentiated calvarial osteoblasts were treated with $100 \mathrm{nM}$ PTHrP $(\operatorname{Pr}), \mathrm{PTH}(\mathrm{P})$, or vehicle $(\mathrm{V})$ for $10 \mathrm{~min}$. Total cellular protein was harvested. Western blot analyses were performed for total ERK $1 / 2$ and phosphorylated ERK1/2. Densitometric analyses were performed, normalized to total ERK1/2, and plotted. Representative data from at least three to four independent experiments are shown. Data are expressed as mean \pm s.D. c, $P<0.05$ versus V. pd, phosphorylationdeficient PTH1R; WT, wild-type.

internalization and phosphorylation in GPCR actions in vivo (Harding et al. 2001), and bone anabolic effects of GRK inhibitor expressed in osteoblasts have been described (Spurney et al. 2002). The physiological actions of PTH1R involve classic $G$ protein-mediated signaling and possibly include multiple GRKs. An influence for $\beta$-arrestin 2 in receptor internalization, bone remodeling, and anabolic effects of intermittent $\mathrm{PTH}(1-34)$ administration was reported using $\beta$-arrestin $2 \mathrm{KO}$ mice (Ferrari \& Bouxsein 2009). The bone phenotype due to the loss of $\beta$-arrestin 2 in the $\mathrm{KO}$ mice may arise from disruption of the functions of a large number of signaling molecules, which include disruption of PTH1R internalization. To specifically understand the physiological role of PTH1R internalization on calcium homeostasis, our group previously developed a KI mouse model, in which the normal Pth $1 r$ gene was replaced with an internalization-impaired pdPTH1R mutant. The pdPTH1R mouse is the only animal model for a phosphorylation-deficient GPCR knocked in the locus of the normal gene using homologous recombination technology. The pd mice showed an exaggerated calcemic response when compared with control animals, given the same dose of $\mathrm{PTH}(1-34)$ infused s.c. over 3 days (Bounoutas et al. 2006). Since serum calcium was normal in the basal state of the pd mouse possibly due to adaptive responses in PTH and phosphate homeostasis, we have used the high and low calcium diets to challenge the adaptive response. Here, we show that a low calcium diet impacts skeletal phenotype of the pdPTH1R and the WT mice without affecting normal growth.

Our previous study showed that under a normal diet, the genetically modified pd animals exhibited normal calcium levels, but PTH levels were one third of those in controls indicating that homeostasis could be maintained only by threefold suppression of PTH secretion (Bounoutas et al.
2006). In this study, we observed that serum PTH levels were suppressed by a high calcium diet in the WT mice but not in the pd mice. However, serum PTH levels were increased in a low calcium diet for both the WT and the pd mice. Interestingly, the low calcium diet did not affect the serum calcium levels but dramatically increased PTH levels; this indicates that adaptive homeostasis responses prevented hypocalcemia both in the WT mice and in the pd mice. In contrast, the high calcium diet increased serum calcium levels only in the female mice. The latter observation suggests a gender-specific mechanism in the maintenance of calcium homeostasis following the high calcium diet. For instance, the low calcium diet resulted in secondary hyperparathyroidism in the WT and the pd mice with similar PTH levels. However, the female pd mice showed significantly lower phosphorus levels on a low calcium diet compared to a normal diet; and both the WT male mice and the pd male mice showed decreased phosphorus in response to a low calcium diet. The lower phosphate level in the female pd mice in a low calcium diet suggests increased PTH action on renal proximal tubular phosphate reabsorption.

In the basal state, loss of PTH1R phosphorylation does not significantly impact bone parameters in the adult mouse. When these mice were stressed with a low calcium diet, we observed bone loss both in the pd and the WT littermates, which was differently affected by the genotype, mostly in female mice, in a site-specific manner. The micro-CT bone

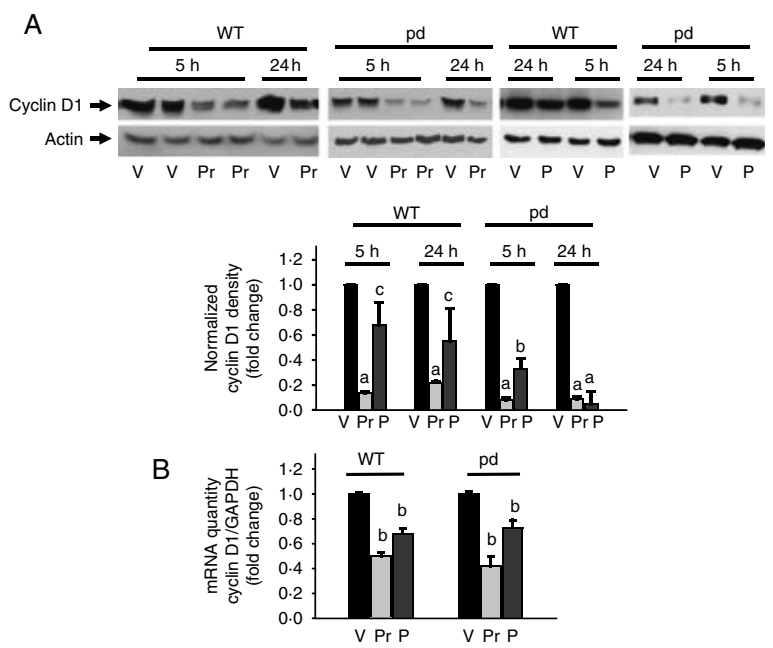

Figure 6 Expression of cyclin D1 in differentiated primary calvarial osteoblasts isolated from the WT and the pd mice. Differentiated calvarial osteoblasts were treated with $100 \mathrm{nM}$ PTHrP $(\mathrm{Pr}), \mathrm{PTH}(\mathrm{P})$, or vehicle (V) for either 5-24 h (A) or $1 \mathrm{~h}(\mathrm{~B})$. Total cellular protein or RNA was harvested. (A) Western blot analyses were performed for cyclin D1 and actin (loading control). Densitometric values were normalized and plotted. (B) Real-time PCR analysis was performed for cyclin D1 mRNA, normalized with GAPDH, and plotted. Representative data from at least three to four independent experiments are shown. Data are expressed as mean \pm s.D. a, $P<0.001$ versus $\mathrm{V} ; \mathrm{b}, P<0.01$ versus $\mathrm{V} ; \mathrm{c}, P<0.05$ versus $\mathrm{V}$. pd, phosphorylation-deficient PTH1R; WT, wild-type. 
parameters of the L 5 vertebra were negatively affected by the pd genotype in the female mice, i.e. the low calcium diet caused more bone loss in the L5 vertebrae of the pd female mice than in the WT female mice. In contrast, those of the distal femur and femur shaft were less affected by the pd genotype during the low calcium diet challenge. This suggests that the molecular and cellular mechanisms affecting bone formation and resorption in the vertebrae and the femur are likely to be different.

PTH stimulates PTH1R to increase intracellular cAMP, which in turn activates PKA leading to phosphorylation of the cAMP-response element-binding protein (CREB). CREB interacts with $\beta$-catenin and regulates its function (Hecht et al. 2000, Takemaru \& Moon 2000). Recently, it has also been proposed that modulation of $\beta$-catenin signaling by cAMP and PKA during stimulation with PTH increases osteoclastogenesis and contributes significantly to the differences observed between Wnt- and PTH-driven responses (Romero et al. 2010), i.e. anabolic or catabolic effect. Bone loss during a low calcium diet is most likely multifactorial, which involves negative calcium balance complicated by secondary hyperparathyroidism aiming at maintaining normocalcemia at the expense of advanced bone resorption. Different bones might be affected differently by the negative calcium balance and/or by the secondary hyperparathyroidism. Bone loss during a low calcium diet apparently exhibits a sexual dimorphism. Since the low calcium diet was initiated at 4 weeks of age and ended at 8 weeks of age, and since ovarian functions in female mice mature approximately at week 6 of age whereas testicular functions in male mice mature at approximately week 8 , it is possible that the differential exposure to gonadal steroid may be responsible for the difference in bone phenotype between male and female during a low calcium diet.

Although loss of PTH1R internalization does not have an effect on overall bone phenotype, the bone changes, summarized in Table 3 , appear to be quite complex, showing mixed results that cannot be fully explained. It is not clear why in the mid-shaft femur the pd genotype appears to possibly partially protective, at least in the females. We can only speculate that sex hormones in combination with impaired internalization of the receptor may contribute to the observed differences in bone response. Sexual dimorphism in skeletal growth, bone loss, and maturation of osteoblasts, or sensitivity to PTH has been described previously using mice deficient in estrogen receptor- $\alpha$, androgen receptor, or both (Vidal et al. 2000, Vandenput et al. 2001, Sims et al. 2002, Tozum et al. 2004). The differences in skeletal phenotype between the male or the female pd mice when challenged with a high or a low calcium diet further suggest contribution of discrete signaling pathways and not a consequence of impaired phosphorylation of PTH1R only. It is known that interaction of several signaling molecules such as $\mathrm{Na}^{+} / \mathrm{H}^{+}$ exchanger regulatory factor (NHERF), calmodulin, calpain, and subunits of the GTP-binding proteins influences the
Table 3 Summary of changes in bone parameters in the male and the female pd mice relative to the WT mice caused by the low calcium diet

\begin{tabular}{|c|c|c|}
\hline Parameters & pd males & pd females \\
\hline \multicolumn{3}{|l|}{ L5 Vert } \\
\hline BV/TV (\%) & $\downarrow$ & $\Leftrightarrow$ \\
\hline TbTh $(\mathrm{mm})$ & $\Leftrightarrow$ & $\Leftrightarrow$ \\
\hline $\mathrm{TbN}(1 / \mathrm{mm})$ & $\Leftrightarrow$ & $\downarrow$ \\
\hline $\mathrm{TbSp}(\mathrm{mm})$ & $\Leftrightarrow$ & $\uparrow$ \\
\hline Conn & $\Leftrightarrow$ & $\Leftrightarrow$ \\
\hline SMI & $\uparrow$ & $\Leftrightarrow$ \\
\hline MinD & $\Leftrightarrow$ & $\Leftrightarrow$ \\
\hline \multicolumn{3}{|l|}{ Distal femur } \\
\hline BV/TV (\%) & $\Leftrightarrow$ & $\uparrow$ \\
\hline TbTh (mm) & $\Leftrightarrow$ & $\Leftrightarrow$ \\
\hline $\mathrm{TbN}(1 / \mathrm{mm})$ & $\Leftrightarrow$ & $\uparrow$ \\
\hline TbSp (mm) & $\Leftrightarrow$ & $\downarrow$ \\
\hline Conn & $\Leftrightarrow$ & $\uparrow$ \\
\hline SMI & $\Leftrightarrow$ & $\downarrow$ \\
\hline MinD & $\uparrow$ & $\Leftrightarrow$ \\
\hline \multicolumn{3}{|c|}{ Mid-shaft femur } \\
\hline TA & $\Leftrightarrow$ & $\Leftrightarrow$ \\
\hline $\mathrm{BA}$ & $\Leftrightarrow$ & $\uparrow$ \\
\hline MA & $\Leftrightarrow$ & $\uparrow$ \\
\hline BA/TA (\%) & $\Leftrightarrow$ & $\uparrow$ \\
\hline Cort Thick & $\Leftrightarrow$ & $\uparrow$ \\
\hline Cort MinD & $\Leftrightarrow$ & $\uparrow$ \\
\hline
\end{tabular}

$\uparrow$, increase; $\downarrow$, decrease; $\Leftrightarrow$, no change; pd, phosphorylation-deficient PTH1R; BV/TV, bone volume/total volume; TbTh, trabecular thickness; TbN, trabecular number; MinD, mineral density, Conn, connectivity; SMI, structure model index; $\mathrm{TA}$, total area; $\mathrm{BA}$, bone area; $\mathrm{MA}$, marrow area; Cort Thick, cortical thickness; Cort MinD, cortical mineral density.

signaling properties of PTH1R (Mahon et al. 2002, 2006, Mahon \& Segre 2004, Mahon \& Shimada 2005, Shimada et al. 2005). Therefore, adaptive responses in these or other molecules may play a role in calcium, phosphate homeostasis and anabolic action, causing a mild phenotype of the pd mice. Regardless of the mechanism, this model may facilitate understanding altered mechanisms of skeletal defects and treating skeletal disorders.

This study suggests that impaired phosphorylation and internalization of PTH1R alone do not significantly impact osteoblast proliferation, differentiation, or mineralization. We have previously demonstrated that down-regulation of cyclin D1 following PTH or PTHrP treatment induces growth arrest in differentiated osteoblasts (Datta et al. 2005); these regulatory events were associated with bone formation in vivo (Datta et al. 2007). We hypothesized that PTH1R regulation of the osteoblast cell cycle plays an important role in its bone anabolic action. Therefore, we have conducted these experiments with the pd osteoblasts, which show sustained PTH1R activity, to explore the molecular mechanism of bone formation. Interestingly, the exaggerated/sustained cAMP response in the pd mice (Bounoutas et al. 2006) reflected the molecular response to PTH in primary calvarial osteoblasts. The down-regulation of cyclin D1 following $\mathrm{PTH}$ or PTHrP treatment was sustained in the pd osteoblasts 
compared to the osteoblasts isolated from the WT or the heterozygous mice. The in vitro osteoblast phenotype is therefore to be contrasted with the mild in vivo bone phenotype. We conclude from these experiments that there are no major differences in molecular regulation of PTH or PTHrP on osteoblasts between the WT and the pd mice, and may partially contribute to similar bone phenotype in these animals. Taken together, it is likely that adaptive responses of intracellular signaling pathway and lower serum PTH concentration in vivo may be important for maintaining bone homeostasis of the pd mice very close to normal.

\section{Declaration of interest}

The authors declare that there is no conflict of interest that could be perceived as prejudicing the impartiality of the research reported.

\section{Funding}

Funding was supported by National Institute of Health Grant DE016865 (to NSD), DK062286 (to ABA-S), and Institutional funding.

\section{Acknowledgements}

The authors wish to thank Bayan Chaker and Rashmi Patil for their technical assistance, and Richard Miller, John D Dingell VA Medical Center, Detroit, for our use of the micro-CT scanner at the VA Medical Center facility.

\section{References}

Abou-Samra AB, Jueppner H, Potts JT Jr \& Segre GV 1989 Inactivation of pertussis toxin-sensitive guanyl nucleotide-binding proteins increase parathyroid hormone receptors and reverse agonist-induced receptor down-regulation in ROS 17/2.8 cells. Endocrinology 125 2594-2599. (doi:10.1210/endo-125-5-2594)

Bellorin-Font E, Lopez C, Diaz K, Pernalete N, Lopez M \& Starosta R 1995 Role of protein kinase $\mathrm{C}$ on the acute desensitization of renal cortical adenylate cyclase to parathyroid hormone. Kidney International 47 38-44. (doi:10.1038/ki.1995.4)

Bounoutas GS, Tawfeek H, Frohlich LF, Chung UI \& Abou-Samra AB 2006 Impact of impaired receptor internalization on calcium homeostasis in knock-in mice expressing a phosphorylation-deficient parathyroid hormone (PTH)/PTH-related peptide receptor. Endocrinology 147 4674-4679. (doi:10.1210/en.2006-0301)

Chao WI \& Forte LR 1982 Rat kidney cells in primary culture: hormonemediated desensitization of the adenosine $3^{\prime}, 5^{\prime}$-monophosphate response to parathyroid hormone and calcitonin. Endocrinology $111252-259$. (doi:10.1210/endo-111-1-252)

Chen C, Koh AJ, Datta NS, Zhang J, Keller ET, Xiao G, Franceschi RT, D'Silva NJ \& McCauley LK 2004 Impact of the mitogen-activated protein kinase pathway on parathyroid hormone-related protein actions in osteoblasts. Journal of Biological Chemistry 279 29121-29129. (doi:10.1074/ jbc.M313000200)

Datta NS \& Abou-Samra AB 2009 PTH and PTHrP signaling in osteoblasts. Cellular Signalling 21 1245-1254. (doi:10.1016/j.cellsig.2009.02.012)

Datta NS, Chen C, Berry JE \& McCauley LK 2005 PTHrP signaling targets cyclin D1 and induces osteoblastic cell growth arrest. Journal of Bone and Mineral Research 20 1051-1064. (doi:10.1359/JBMR.050106)
Datta NS, Pettway GJ, Chen C, Koh AJ \& McCauley LK 2007 Cyclin D1 as a target for the proliferative effects of PTH and PTHrP in early osteoblastic cells. Journal of Bone and Mineral Research 22 951-964. (doi:10.1359/jbmr. 070328)

Datta NS, Kolailat R, Fite A, Pettway G \& Abou-Samra AB 2010 Distinct roles for mitogen-activated protein kinase phosphatase-1 (MKP-1) and ERKMAPK in PTH1R signaling during osteoblast proliferation and differentiation. Cellular Signalling 22 457-466. (doi:10.1016/j.cellsig.2009.10.017)

Drueke TB 1996 Abnormal skeletal response to parathyroid hormone and the expression of its receptor in chronic uremia. Pediatric Nephrology $10348-350$. (doi:10.1007/BF00866780)

Ferrari SL \& Bouxsein ML 2009 -Arrestin-biased parathyroid hormone ligands: a new approach to the development of agents that stimulate bone formation. Science Translational Medicine 1 1ps1. (doi:10.1126/scitranslmed. 3000268)

Gordeladze JO, Mortensen B, Nordal K, Halse J, Dahl E, Aksnes L \& Gautvik KM 1987 The effect of parathyroid hormone (PTH) and 24,25-dihydroxyvitamin $\mathrm{D}_{3}$ on adenylyl cyclase of iliac crest biopsies: diagnostic and prognostic tool for evaluation and treatment of uremic patients. Scandinavian Journal of Clinical and Laboratory Investigation. Supplement 186 13-20.

Harding VB, Jones LR, Lefkowitz RJ, Koch WJ \& Rockman HA 2001 Cardiac $\beta$ ARK1 inhibition prolongs survival and augments $\beta$ blocker therapy in a mouse model of severe heart failure. PNAS 98 5809-5814. (doi:10.1073/pnas.091102398)

Hecht A, Vleminckx K, Stemmler MP, van Roy F \& Kemler R 2000 The p300/CBP acetyltransferases function as transcriptional coactivators of $\beta$-catenin in vertebrates. EMBO Journal 19 1839-1850. (doi:10.1093/ emboj/19.8.1839)

Jongen JW, Willemstein-van Hove EC, van der Meer JM, Bos MP, Juppner H, Segre GV, Abou-Samra AB, Feyen JH \& Herrmann-Erlee MP 1996 Down-regulation of the receptor for parathyroid hormone (PTH) and PTH-related peptide by PTH in primary fetal rat osteoblasts. Journal of Bone and Mineral Research 11 1218-1225. (doi:10.1002/jbmr.5650110905)

Lefkowitz RJ, Pitcher J, Krueger K \& Daaka Y 1998 Mechanisms of $\beta$-adrenergic receptor desensitization and resensitization. Advances in Pharmacology 42 416-420. (doi:10.1016/S1054-3589(08)60777-2)

Mahon MJ \& Segre GV 2004 Stimulation by parathyroid hormone of a NHERF-1-assembled complex consisting of the parathyroid hormone I receptor, phospholipase $C \beta$, and actin increases intracellular calcium in opossum kidney cells. Journal of Biological Chemistry $27923550-23558$. (doi:10.1074/jbc.M313229200)

Mahon MJ \& Shimada M 2005 Calmodulin interacts with the cytoplasmic tails of the parathyroid hormone 1 receptor and a sub-set of class b G-protein coupled receptors. FEBS Letters 579 803-807. (doi:10.1016/j. febslet.2004.12.056)

Mahon MJ, Donowitz M, Yun CC \& Segre GV $2002 \mathrm{Na}(+) / \mathrm{H}(+)$ exchanger regulatory factor 2 directs parathyroid hormone 1 receptor signalling. Nature 417 858-861. (doi:10.1038/nature00816)

Mahon MJ, Bonacci TM, Divieti P \& Smrcka AV 2006 A docking site for G protein $\beta \gamma$ subunits on the parathyroid hormone 1 receptor supports signaling through multiple pathways. Molecular Endocrinology 20 136-146. (doi:10.1210/me.2005-0169)

Marsh ME, Munne AM, Vogel JJ, Cui Y \& Franceschi RT 1995 Mineralization of bone-like extracellular matrix in the absence of functional osteoblasts. Journal of Bone and Mineral Research 10 1635-1643. (doi:10. 1002/jbmr.5650101105)

Mitchell J \& Goltzman D 1990 Mechanisms of homologous and heterologous regulation of parathyroid hormone receptors in the rat osteosarcoma cell line UMR-106. Endocrinology 126 2650-2660. (doi:10.1210/endo-126-5-2650)

Oakley RH, Laporte SA, Holt JA, Barak LS \& Caron MG 2001 Molecular determinants underlying the formation of stable intracellular $G$ proteincoupled receptor- $\beta$-arrestin complexes after receptor endocytosis. Journal of Biological Chemistry 276 19452-19460. (doi:10.1074/jbc.M101450200)

Olgaard K, Arbelaez M, Schwartz J, Klahr S \& Slatopolsky E 1982 Abnormal skeletal response to parathyroid hormone in dogs with chronic uremia. Calcified Tissue International 34 403-407. (doi:10.1007/BF02411275) 
Pitcher JA, Freedman NJ \& Lefkowitz RJ 1998 G protein-coupled receptor kinases. Annual Review of Biochemistry 67 653-692. (doi:10.1146/annurev. biochem.67.1.653)

Romero G, Sneddon WB, Yang Y, Wheeler D, Blair HC \& Friedman PA 2010 Parathyroid hormone receptor directly interacts with dishevelled to regulate $\beta$-catenin signaling and osteoclastogenesis. Journal of Biological Chemistry 285 14756-14763. (doi:10.1074/jbc.M110.102970)

Shimada M, Mahon MJ, Greer PA \& Segre GV 2005 The receptor for parathyroid hormone and parathyroid hormone-related peptide is hydrolyzed and its signaling properties are altered by directly binding the calpain small subunit. Endocrinology 146 2336-2344. (doi:10.1210/en. 2004-1637)

Sims NA, Dupont S, Krust A, Clement-Lacroix P, Minet D, Resche-Rigon M, Gaillard-Kelly M \& Baron R 2002 Deletion of estrogen receptors reveals a regulatory role for estrogen receptors- $\beta$ in bone remodeling in females but not in males. Bone 30 18-25. (doi:10.1016/S87563282(01)00643-3)

Spurney RF, Flannery PJ, Garner SC, Athirakul K, Liu S, Guilak F \& Quarles LD 2002 Anabolic effects of a G protein-coupled receptor kinase inhibitor expressed in osteoblasts. Journal of Clinical Investigation 109 1361-1371. (doi:10.1172/JCI200214663)

Takemaru KI \& Moon RT 2000 The transcriptional coactivator CBP interacts with $\beta$-catenin to activate gene expression. Journal of Cellular Biology 149 249-254. (doi:10.1083/jcb.149.2.249)

Tamayo J, Bellorin-Font E, Sicard G, Anderson C \& Martin KJ 1982 Desensitization to parathyroid hormone in the isolated perfused canine kidney: reversal of altered receptor-adenylate cyclase system by guanosine triphosphate in vitro. Endocrinology 111 1311-1317. (doi:10.1210/endo111-4-1311)

Tawfeek HA, Qian F \& Abou-Samra AB 2002 Phosphorylation of the receptor for $\mathrm{PTH}$ and $\mathrm{PTHrP}$ is required for internalization and regulates receptor signaling. Molecular Endocrinology 16 1-13. (doi:10. 1210/me.16.1.1)

Tozum TF, Oppenlander ME, Koh-Paige AJ, Robins DM \& McCauley LK 2004 Effects of sex steroid receptor specificity in the regulation of skeletal metabolism. Calcified Tissue International 75 60-70. (doi:10.1007/s00223004-0119-8)

Vandenput L, Ederveen AG, Erben RG, Stahr K, Swinnen JV, Van Herck E, Verstuyf A, Boonen S, Bouillon R \& Vanderschueren D 2001 Testosterone prevents orchidectomy-induced bone loss in estrogen receptor- $\alpha$ knockout mice. Biochemical and Biophysical Research Communications 285 70-76. (doi:10.1006/bbrc.2001.5101)

Vidal O, Lindberg MK, Hollberg K, Baylink DJ, Andersson G, Lubahn DB, Mohan S, Gustafsson JA \& Ohlsson C 2000 Estrogen receptor specificity in the regulation of skeletal growth and maturation in male mice. PNAS 97 5474-5479. (doi:10.1073/pnas.97.10.5474)

Received in final form 5 October 2010

Accepted 7 October 2010

Made available online as an Accepted Preprint 7 October 2010 